\title{
The Effect of Various Paving Time on the Time Available for Compaction of Warm Mix Asphalt (WMA)
}

\author{
Nurul Syahirah Fatinah Mustapa, Wardati Hashim, Ahmad Kamil Arshad, Ekarizan Shaffie, \\ Zanariah Abd. Rahman
}

\begin{abstract}
Warm Mix Asphalt (WMA) is a technology that allows significant lowering of the production and paving temperature of conventional Hot Mix Asphalt (HMA). By reducing the viscosity of bitumen and/or increasing the workability of mixture, some WMA technologies can reduce the temperature to even lower without compromising the performance of asphalt. High demand for new asphalt pavements often requires that paving is to be done in an unfavorable condition such as low air temperatures, high wind speeds, and night construction that will influence the cooling rate of asphalt pavements, affecting the Time Available for Compaction (TAC). TAC is a period taken by the asphalt mix to cool and stiff to the point where it can absorb the applied compaction energy without allowing the aggregate particles to move and avoid higher cooling rate which will reduce the TAC. In local practice, the asphalt paving compaction control mechanisms quoted from the locally used specifications are normally based on the limits of the delivery and laying completion temperatures. There are no items that can be used to predict these control elements and to be specifically related to the local conditions. This study was conducted with the aim to determine the appropriate TAC of WMA when paved at different time (day and night) through laboratory tests. It focused on WMA AC 14 of mix type for wearing course and AC 28 of mix type for binder course. The results indicated that the cooling rate of WMA is significantly affected by the amount of solar flux (on daytime), ambient and base temperature thus influencing the Time Available for Compaction (TAC). The TAC tends to increase during daytime at 1pm as compared to 9am, 5pm and during night time.
\end{abstract}

Keywords : Warm Mix Asphalt (WMA), Cooling rate, Time Available for Compaction (TAC), Paving Time

\section{INTRODUCTION}

HMA is produced at temperatures between $140^{\circ} \mathrm{C}$ and $160^{\circ} \mathrm{C}$ [1]. These temperatures ensure that the aggregate is dry, the asphalt binder coats the aggregate, and the HMA mix has a suitable workability. HMA needs to be workable, so that it can be transferred into storage silos, transported, placed, and compacted. WMA technology is now available to decrease HMA production temperatures as much as $40^{\circ} \mathrm{C}$.

Revised Manuscript Received on October 22, 2019.

Nurul Syahirah Fatinah, Postgraduate Student, Faculty of Civil Engineering, Universiti Teknologi MARA (UiTM), Malaysia.

Wardati Hashim, Senior Lecturer, Faculty of Civil Engineering, UiTM Shah Alam, Malaysia.

Ahmad Kamil Arshad, Graduated with a $\mathrm{PhD}$ in Civil Engineering from Universiti Teknologi MARA (UiTM), Shah Alam.

Ekarizan Shaffie, Principal Researcher, Institute for Infrastructure Engineering and Sustainability Management (IIESM), Universiti Teknologi MARA (UiTM), Shah Alam.

Zanariah Abdul Rahman, Senipor Lecture, Universiti Teknologi MARA (UiTM), Pulau Pinang.
Reducing HMA production and placement temperatures will provide several benefits, including reduced emissions, fumes, and odors as well as a cooler work environment. An energy saving from lower production temperatures is evident with the use of warm mix asphalt technologies.

The same mechanisms that allow WMA to improve workability at lower temperatures also allow WMA technologies to act as compaction aids. Improved compaction or in-place density tends to reduce permeability and binder hardening due to aging, which tends to improve performance in terms of cracking resistance and moisture susceptibility. Temperature is one of the maximum important factors affecting the design and overall performance of each inflexible and bendy pavements. Temperature versions within the pavement structure contributes in many special approaches to pavement misery and viable failure of that structure [2]. A research was carried out by Lin et al [3]., who located that the surface temperature of artificial pavements in Taiwan is $10{ }^{\circ} \mathrm{C}$ higher than that of the flora surface at midday within the summer, but the difference the various numerous pavement kinds is not clearly substantial at some stage in wintry weather. Qin and Hiller discovered that the each day temperature amplitude influences the temperature distribution across a pavement slab during the daytime extra than throughout the night time [4].

Compaction beneath the usual compaction temperature may additionally convey reverse impact on asphalt pavements properties. The time available for compaction (TAC) is one of the primary controlling elements at some stage in the compaction technique [5]. TAC is defined as a length taken by means of the asphalt pavements to cool and stiffen to the factor in which it could soak up the implemented compaction strength without allowing the combination debris to move [6]. It is nicely documented that the time required for compaction decreases with growing cooling rate. As a result, the potential to expect the cooling rate is more critical all through negative conditions, because the time to be had for mix compaction is restrained [7]. Low air temperatures, excessive winds and night construction create damaging

situations for asphalt paving and those factors in the end influence the cooling rate and have an effect on the compaction method in addition to the TAC.

The unmarried maximum vital element that probable influences the compaction is the temperature on the time of compaction $[8,9,10]$. One examine of TAC discusses the cooling rate of asphalt pavements, and reveals that the elements affecting the cooling rate encompass the initial

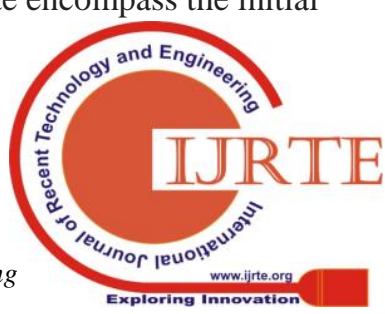


temperature at the time of placement, the air temperature of the base, the thickness of the asphalt mix layer and environmental conditions. According to Corlew and Dickson [11], they performed a look at of TAC to decide the deadlines for compaction via specifying a minimum compaction temperature of $80{ }^{\circ} \mathrm{C}$. At temperatures beneath $80^{\circ} \mathrm{C}$ the chance of significantly increasing density could be very low and, in some instances, can result in the fracture of the combination in the mix and a decrease in density.

This study was carried out to evaluate how the cooling rate of the asphalt pavement at particular thicknesses of wearing path and binder course is suffering from the local situations which include environmental effect of paving time on the determination of TAC which might lead to seriously better manage and specification in the course of the compaction procedure in the local enterprise.

\section{EXPERIMENTAL DESIGN}

\section{A. Materials}

Bitumen, additives and mineral aggregates will be described in the next subchapters.

\section{B. Bitumen}

For this research, an asphalt with penetration grade 60/70 used, according with the Malaysian PWD JKR/SPJ/2008-S4 [12].

\section{Additives}

The chemical additive used in this study to modify the HMA was Cecabase RT. Cecabase RT, a liquid additive, from CECA, a subsidiary of the Arkema Group, is a chemical additive that provides workability to the asphalt mixtures at lower temperatures using standard dosage between 0.2 to 0.5 percent of CECABASE per unit weight in asphalt. According to their producers this additives is surfactant products that act at the microscopic interface between the aggregates and bitumen, reducing the internal frictional forces and ensuring the workability and compactability of the bituminous mixture produced and compacted at lower temperatures [13]. Cecabase RT is a surface active agent that can be directly applied into the hot binder. This additive is a liquid with a density of about $8.30 \mathrm{lbs} / \mathrm{gal}$ and a flash point of $199^{\circ} \mathrm{C}$.

\section{Mineral Aggregates}

The aggregate kind used on this study was properly-graded crushed granite aggregate. Like the binder, the AC14 mix type for the wearing course and AC28 mix type for the binder course for both HMA and WMA samples were organized in accordance with the Malaysian PWD JKR/SPJ/2008-S4. The aggregates for each AC14 and AC28 for HMA and WMA additionally were sieved into their respective size levels or fractions and batched to comply to the combination grading requirements. The unique gravity (SG) for the fine aggregate (ASTM C 128) and the coarse aggregate (ASTM C 127) and the proportion of required mineral filler content in the aggregate gradation for HMA and WMA have been decided. Eventually, the Theoretical maximum Density (TMD) for every mixes were measured via the Rice technique test. Table 2 indicates the outcomes acquired on this examine.

\section{E. Mix Designs}

The usual Marshall mix design technique from the Malaysian PWD JKR/SPJ/2008-S4 (Malaysian Public Works Department, 2008)was applied to design the HMA mixes for dedication of Optimum Bitumen Content (OBC) and WMA mixes for determination of Optimum Cecabase Content (OCC). The $\mathrm{OBC}$ for $\mathrm{AC} 14$ and $\mathrm{AC} 28$ determined from HMA samples testing are $4.9 \%$ and $4.3 \%$ respectively. This OBC of HMA was used for WMA mix testing to determine OCC. The OCC for AC14 and AC28 were $0.3 \%$ and $0.26 \%$ respectively, will were used in preparing the slab sample for temperature test. The volumetric properties of all PWD Marshall Mixes conformed to the Malaysian PWD JKR/SPJ/2008-S4 (Malaysian Public Works Department, 2008). Table 1 shows the volumetric properties of WMA designed.

\section{F. Temperature Measurements}

Temperature measurement test was meant to measure the cooling rate as the temperature drops along time, affected due to the paving time. Samples of WMA were prepared in a slab mold of size $30.5 \mathrm{~cm}$ width and $30.5 \mathrm{~cm}$ long with the height of $7 \mathrm{~cm}$ for controlled samples and temperature measurement samples, as shown in Figure 1. Slab mold was used to describe sample as in same shape of actual pavement. The slab inside surface area was calculated to provide a thickness to length ratio less than or equal to 0.2. According to Fwa et al. [14] stated that this limiting ratio for square slab is to ensure that the temperature variations at a mid-slab position can be modelled using one dimensional plan-wall theory. Temperature at the surface of slab sample was measured using the thermo-heatgun while at the middle slab was measured using the thermo-heatgun while at the middle slab was measured using the thermocouples wires which can be plugged into a multi-channel thermocouple reader.

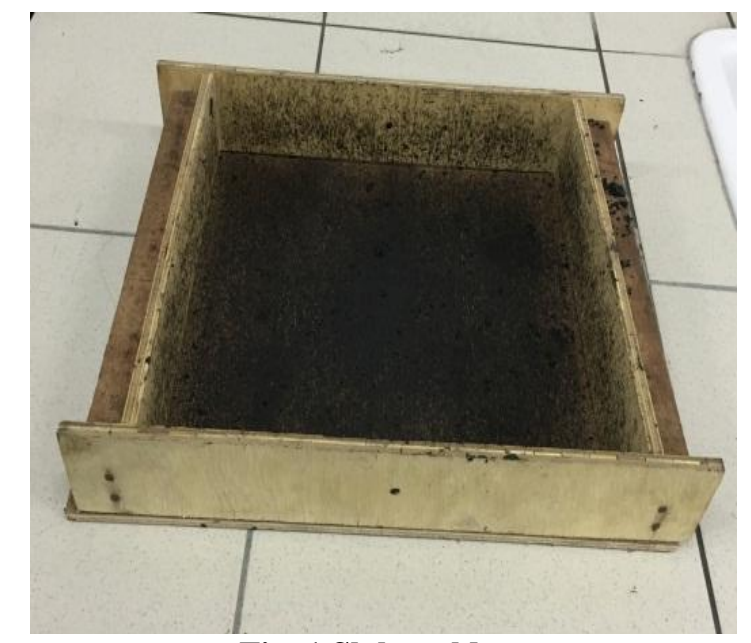

Fig. 1 Slab mold

Tests were conducted during daytime and night time. For the daytime, tests were conducted at $9 \mathrm{am}, 1 \mathrm{pm}$ and $5 \mathrm{pm}$. 
Table 1 Volumetric Properties of AC14 and AC28 for WMA

\begin{tabular}{|l|c|c|c|c|}
\hline $\begin{array}{c}\text { Volumetri } \\
\text { c } \\
\begin{array}{c}\text { Propertie } \\
\text { s }\end{array}\end{array}$ & AC14 & $\begin{array}{c}\text { Specificatio } \\
\mathbf{n}\end{array}$ & $\begin{array}{c}\text { AC28 } \\
\text { Specificatio } \\
\mathbf{n}\end{array}$ \\
\hline OBC, \% & 4.9 & $4.0-6.0$ & 4.3 & $3.5-5.5$ \\
\hline OCC, \% & 0.3 & $0.2-0.4$ & 0.26 & $0.2-0.4$ \\
\hline $\begin{array}{l}\text { Stability } \\
(\text { S), N }\end{array}$ & 10110 & $>8000$ & 21000 & $>8000$ \\
\hline $\begin{array}{l}\text { Flow (F), } \\
\text { mm }\end{array}$ & 2.74 & $2.0-4.0$ & 3.3 & $2.0-4.0$ \\
\hline $\begin{array}{l}\text { Stiffness, } \\
\text { N/mm }\end{array}$ & 3689. & $>2000$ & 6363. & $>2000$ \\
\hline VIM, \% & 3.85 & $3.0-5.0$ & 3.9 & $3.0-7.0$ \\
\hline VFB, \% & 76.2 & $70-80$ & 65.2 & $65-75$ \\
\hline
\end{tabular}

While for the night time, 9pm, 1am and 5am were chosen as the various time of paving respectively. During daytime, the samples for AC14 and AC28 were placed directly outside the laboratory under the effect of sunlight. The test recorded the solar flux value as well as base and ambient temperature according to the test time. Temperature was recorded for every one minute. The controlled sample for AC14 and AC28 also were tested in the highway laboratory without any influence of sunlight at a constant base temperature of $28^{\circ} \mathrm{C}$ and ambient temperature of $29^{\circ} \mathrm{C}$ to compare the difference in cooling rate and TAC.

\section{RESULTS AND DISCUSSION}

In paving process, cooling of asphalt pavements needed to be discovered nicely as when compaction technique take vicinity, there need to be sufficient time to do for the reason that pavements when cool to ambient temperature, it turns into stiff enough and resists to any compactive attempt that could cause inadequate compaction. Figure 2 describes the instance of the connection among temperature and the cooling time of HMA. There was a sluggish drop of HMA temperature upon unique time until it will become strong. Now and again, the mixture has a tendency to chill as warmness begins to loss. Consequently, the temperature will then start to drop until it reaches the ambient temperature and the mixture turns into stiff enough to sustain traffic load.

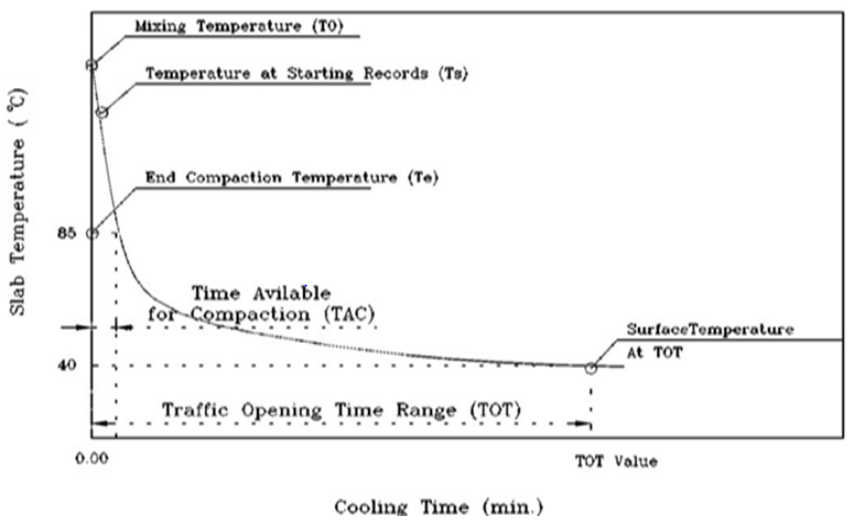

Figure 2 Graph of slab (HMA) temperature versus cooling time (Source: Jendia and Jarada, 2005)

Table 2 Cooling rate at $\mathbf{1 0}$ minutes interval for $\mathbf{3 0}$ minutes time

\begin{tabular}{|c|c|c|c|c|c|c|}
\hline Mix-Type & \multicolumn{3}{|c|}{ AC14 } & \multicolumn{3}{|c|}{$\mathrm{AC28}$} \\
\hline Time (min) & & & & & & \\
\hline Test & 10 & 20 & 30 & 10 & 20 & 30 \\
\hline $\begin{array}{l}\text { Paving at } \\
\text { Daytime }\end{array}$ & \multicolumn{3}{|c|}{ Cooling Rate $\left({ }^{\circ} \mathrm{C} / \mathrm{min}\right)$} & \multicolumn{3}{|c|}{ Cooling Rate $\left({ }^{\circ} \mathrm{C} / \mathrm{min}\right)$} \\
\hline Control & 1.84 & 0.88 & 1 & 2.72 & 1.18 & 0.83 \\
\hline 9.00am & 1.74 & 1 & 1 & 1.21 & 1.27 & 1.22 \\
\hline $1.00 \mathrm{pm}$ & 1.14 & 1 & 0.92 & 1.2 & 0.9 & 0.75 \\
\hline $5.00 \mathrm{pm}$ & 1.22 & 0.74 & 1 & 1.24 & 0.84 & 0.8 \\
\hline $\begin{array}{c}\text { Paving at } \\
\text { Night Time }\end{array}$ & \multicolumn{3}{|c|}{ Cooling Rate $\left({ }^{\circ} \mathrm{C} / \mathrm{min}\right)$} & & \multicolumn{2}{|c|}{ Cooling Rate $\left({ }^{\circ} \mathrm{C} / \mathrm{min}\right)$} \\
\hline Control & 1.84 & 0.88 & 1 & 2.72 & 1.18 & 0.83 \\
\hline $9.00 \mathrm{pm}$ & 2.44 & 0.95 & 0.85 & 2.6 & 1.33 & 0.98 \\
\hline $1.00 \mathrm{am}$ & 2.41 & 1.11 & 1.03 & 2.39 & 1.17 & 1.18 \\
\hline $5.00 \mathrm{am}$ & 2.75 & 1 & 1.05 & 2.43 & 1.98 & 0.92 \\
\hline
\end{tabular}

\section{A. Analysis of Cooling Rate $\left({ }^{\circ} \mathrm{C} / \mathrm{min}\right)$}

Cooling rate was acquired from the slope of the trend line applied to the scatter graph of records received at 10 minutes periods over 30 minutes. Based on the tests conducted, the temperature reduction of WMA was critical during the primary 30 minutes. Cooling rate inside this 30 minutes duration shall indicate the trend of the TAC result obtained.

Table 2 displays the result of cooling rate at 10 minutes periods over half-hour for each test performed. 
The result shows that during daytime, especially $1 \mathrm{pm}$, the cooling rate is the lowest for both AC14 and AC28. This is due to the presence of high solar flux, base and ambient temperature during that time. This indicates that the number of solar intensity would slow down the pavement cooling process. The highest cooling rate was noticed at 9am for both mixes, since the amount of solar flux, base and ambient temperature at that time much lower compared to $1 \mathrm{pm}$ and $5 \mathrm{pm}$. While paving work during night time shows higher cooling rate compared to daytime due to solar flux non-existence condition and lower base and ambient temperature. The result shows that the cooling rate increases from early night to early morning. Hashim [15] found the same pattern of cooling rate scenario tested on Hot Mix Asphalt (HMA).

\section{B. Time Available for Compaction}

TAC is the indicator of how sufficient the time contractors have to compact and achieve the durability of the pavement, from the laying temperature to the cutting point of $80^{\circ} \mathrm{C}$ of temperature. Compaction at lower than $80^{\circ} \mathrm{C}$ will result to bad durability Difference paving time will be indicated by different solar flux, base and ambient temperature thus affecting the cooling time and TAC. Controlled sample was tested in laboratory at controlled base and ambient temperature. The result in Figure 3(a) and 3(b) shows that in average both $\mathrm{AC} 14$ and $\mathrm{AC} 28$ have more than 40 minutes TAC before the sample temperature reach $80^{\circ} \mathrm{C}$, during daytime. Sample tested at $1 \mathrm{pm}$ for both AC14 and AC28 give the highest TAC which is at 51 minutes and 52 minutes respectively.

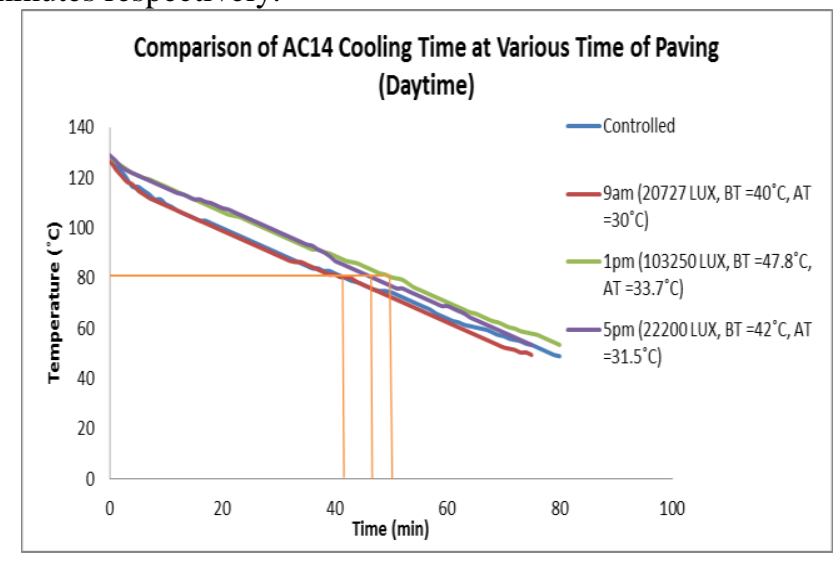

(a)

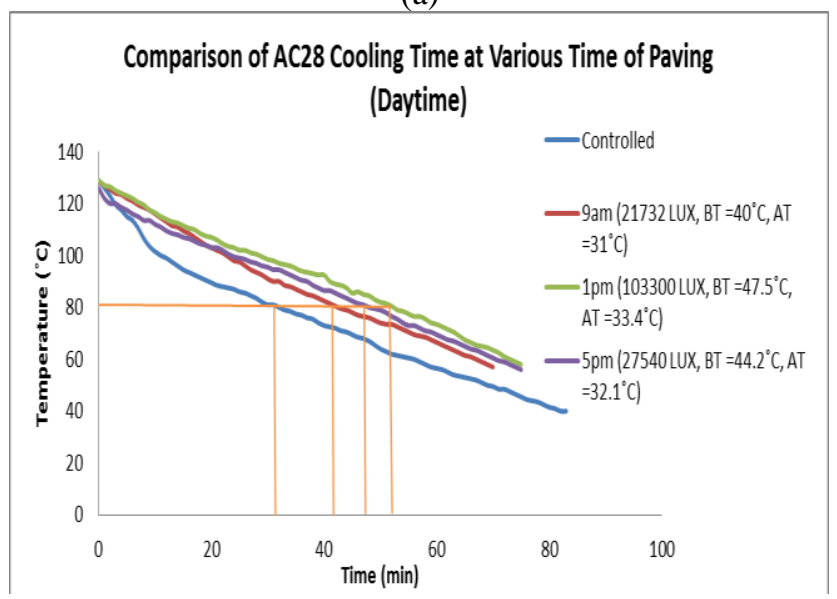

(b)

\section{Fig. 3 Comparison of Cooling Time at Various Paving Time (Daytime)}

Figure 4(a) and 4(b) shows the cooling time of both mixes tested at various night time which indicated only by base and ambient temperature. The result shows that in average both mixes have around TAC 30minutes for before the temperature reach $80^{\circ} \mathrm{C}$, as compare to controlled sample. Paving time at $5 \mathrm{am}$ shows the lowest TAC for both AC14 and AC28 at 29 minutes and 21 minutes respectively.

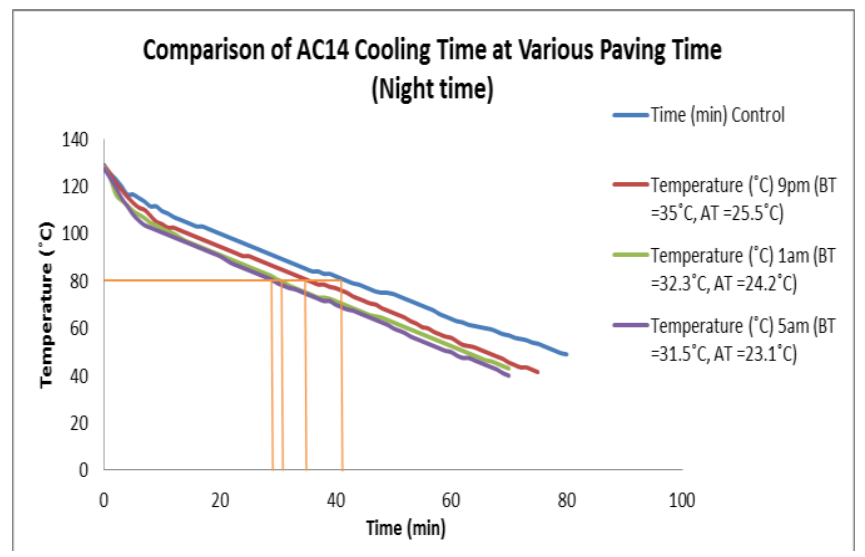

(a)

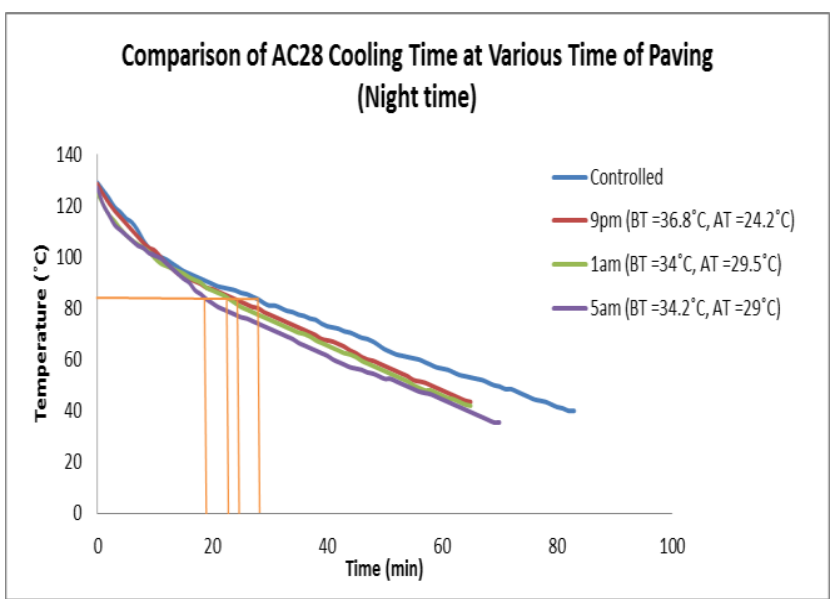

(b)

Fig. 4 Comparison of Cooling Time at Various Paving Time (Night time)

Results in Table 3 shows the summary of TAC for both mixes tested at different paving time which indicates the TAC is longer for paving works during daytime compared to the night time. This could be due to the low cooling rates during daytime since there are presences of solar flux effects. Generally, TAC during daytime increase between 2-61\% longer compared to controlled sample. While TAC during night time is between $12-34 \%$ lower than controlled sample tested which is due to non-existence of solar flux and lower base and ambient temperature. 
Table 3 Evaluation of TAC for Various Paving Time Test

\begin{tabular}{|c|c|c|c|c|c|c|c|c|}
\hline Mix Type & \multicolumn{4}{|c|}{ AC14 } & \multicolumn{4}{|c|}{$\mathrm{AC28}$} \\
\hline $\begin{array}{l}\text { Paving } \\
\text { Time } \\
\text { (Daytime) }\end{array}$ & Control & $9 \mathrm{am}$ & $1 \mathrm{pm}$ & $5 \mathrm{pm}$ & Control & $9 \mathrm{am}$ & $1 \mathrm{pm}$ & $5 \mathrm{pm}$ \\
\hline TAC & 42 & 43 & 51 & 47 & 32 & 42 & 52 & 48 \\
\hline $\begin{array}{c}\text { Increment } \\
(\%)\end{array}$ & & 2.38 & 21.43 & 11.9 & & 31.25 & 62.5 & 50 \\
\hline $\begin{array}{l}\text { Paving } \\
\text { Time } \\
\text { (Night } \\
\text { time) }\end{array}$ & Control & $9 \mathrm{pm}$ & $1 \mathrm{am}$ & $5 \mathrm{am}$ & Control & $9 \mathrm{pm}$ & $1 \mathrm{am}$ & $5 \mathrm{am}$ \\
\hline TAC & 42 & 35 & 30 & 29 & 32 & 28 & 24 & 21 \\
\hline $\begin{array}{c}\text { Reduction } \\
(\%)\end{array}$ & & 16.67 & 28.57 & 30.95 & & 12.5 & 25 & 34.38 \\
\hline
\end{tabular}

\section{CONCLUSION}

Surface and ambient temperature are generally higher during daytime because of the presence of the solar flux which would increase the TAC of WMA pavement that affected by the reducing of cooling rate. As compared to night time, the TAC is slightly lowerdaytime as there was no solar flux existence and the temperature of surface and ambient were much lower, thus it would increases the cooling rate of WMA. The results clearly indicate that the paving works done during daytime will decrease the value of cooling rate thus,there is more time for compaction work to take place.Hence, it can be concluded that the cooling rate of WMA is significantly affected by the paving time, thus influencing the TAC process to take place. This study has given the results on the TAC which can be practiced in local pavement construction industry. However, due to less number of samples and other limitations, the results could only be applied as general indicator since the environmental effects involve lots of factors which are truly depend on local condition.

\section{ACKNOWLEDGEMENT}

The authors would like to acknowledge Ministry of Education Malaysia (MOE) and Research Management Institute (RMI), UiTM for the funding and financial supports of Fundamental Research Grant Scheme (FRGS); Ref: 600-IRMI/FRGS 5/3(091/2017). Special thanks to the management of Faculty of Civil Engineering and Institute for Infrastructure Engineering and Sustainable Management, UiTM for the constant support.

\section{REFERENCES}

1. Goh, Shu Wei, Ph.D., P.E., Zhanping You and Ph.D., P.E., Thomas J Van Dam (2007). Laboratory Evaluation and Pavement Design for Warm Mix Asphalt. Mid-Continent Transportation Research Symposium. Ames, Iowa: Iowa State University, 2007.

2. Ramadhan, R.H. and Al-Abdul Wahhab, H.I. (1997). Temperature variation of flexible and rigid pavements in eastern saudi arabia. Building and Environment. 32(4): 367-373

3. Lin, T. P., Y.F, Ho, and Huang, Y.S . (2007). Seasonal effect of pavement on outdoor thermal environments in subtropical taiwan. Building and Environment. 42(12): 4124-4131.

4. Qin, Y. and Hiller, J.E. (2011).Modeling temperature distribution in rigid pavement slabs: impact of air temperature. Construction and Building Materials. 25(9): 3753-376

5. Newcomb, D.E., Chadbourn, B.A., Luoma, J.A. and Volleri, V.R. (1996). Consideration of Hot-Mix Asphalt Thermal Properties during Compaction. American Society for Testing and Material, ASTM STP 1299.

6. Jendia, S. and Jarada, A. (2005).Traffic Opening Time and Time Available for Compaction for Fresh Asphalt Layer using Slab Specimens Model. The Islamic University Journal (Series of Natura Studies and Engineering). 14(1): 11-35.
7. Hughes, C.S. (1989). NCHRP Synthesis of Highway Practice 152: Compaction of Asphalt Pavement. Transportation Research Board: Washington, D.C.

8. Idham, M. K., Hainin, M.R., Yaacob, H., Warid, M.N and Abdullah, M.E. (2013). Effect of aging on resilient modulus of hot mix asphalt mixtures. Advanced Materials Research.723: 291-297.

9. Ahmad, J., Rahman, M.Y.A and Hainin, M.R. (2011). Rutting evaluation of dense graded hot mix asphalt mixture. International Journal of Engineering \& Technology.11(05): 56-60.

10. Chang, C.M., Chang,Y.J. and Chen, J.S. (2009). Effect of mixture characteristics on cooling rate of asphalt pavements. ASCE J Tran Eng.135: 297-304.

11. Corlew, J.S. and Dickson, P.F. (1968). Methods for calculating temperature profiles of hot-mix asphalt concrete as related to the construction of asphalt pavements. Proc Assoc Asphalt Paving Technol. 37: 101-140.

12. Malaysian Public Works Department. 2008. Standard Specification for Road Works Section 4: Flexible Pavement. JKR/SPJ/2008-S4: Kuala Lumpur.

13. Anderson, R. M., G. Baumgardner, et al. (2008). Engineering Properties, Emissions, and Field Performance of Warm Mix Asphalt Technology, National Cooperative Highway Research Program (NCHRP).

14. Fwa, T.F., Low, B.H. and Tan, S.A. 1995.Laboratory Determination of Thermal Properties of Asphalt Mixture by Transient Heat Conduction Method. A Paper Presented at the Annual Meeting of the Transportation Research Board: Washington DC.

15. Hashim, W., Hainin, M. R., Ismail, N. N., Yusoff, N. I. M., Abdullah, M. E., \& Hassan, N. A. (2016). Evaluating the cooling rate of hot mix asphalt in tropical climate. Jurnal Teknologi, 78(4).

\section{AUTHORS PROFILE}

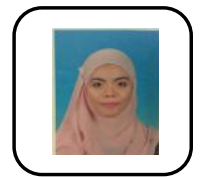

Nurul Syahirah Fatinah is a postgraduate student in FAculty of Civil Engineering, Universiti Teknologi MARA (UiTM), Malaysia. She is currently pursuing her Masters in Highway Engineering.

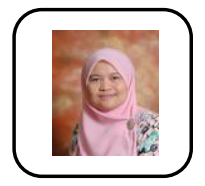

Wardati Hashim has been involving in higher education for 11 years related to Civil Engineering study, specializing in Highway and Traffic Engineering. She acquired $\mathrm{PhD}$ in Civil Engineering from Universiti Teknologi Mara (UiTM). Currently a Senior Lecturer at Faculty of Civil Engineering, UiTM Shah Alam, her areas of interest/expertise include traffic engineering statistical analysis, sustainable transportation and pavement material evolution in highway engineering.

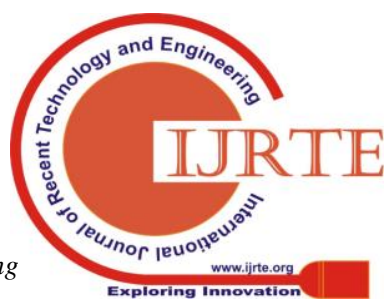


Ahmad Kamil Arshad graduated with a $\mathrm{PhD}$ in Civil Engineering from Universiti Teknologi MARA (UiTM), Shah Alam. He is a registered professional engineer with more than 20 years experience prior to joining UiTM. In 2003, he headed the pioneer Hot In-Place Recycling Division of HCM Engineering Sdn Bhd and was involved in the development of REAM Specification for HIPR.

Ekarizan Shaffie is currently is principal researcher at the Institute for Infrastructure Engineering and Sustainability Management (IIESM), Universiti Teknologi MARA (UiTM), Shah Alam. She graduated with a Msc and $\mathrm{PhD}$ in Civil Engineering from UiTM. She has 12 years experrience in research, consultancy and training works with various organization in Malaysia. Her research interest focus on sustainable and green highway materials and pavement engineering.

Zanariah Abdul Rahman is currently a Senipor Lecture at Universiti Teknologi MARA (UiTM), Pulau Pinang. She graduated with a Msc in Highway \& Transportation Engineering from Univeristi Teknologi Malaysia. She has 11 years experience in research, consultancy and training works with various organization in Malaysia. 